\title{
Development of a Health Workeforce Monitoring System in Greece
}

\author{
Christos Zilidis ${ }^{1}$, Catherine Kastanioti ${ }^{2}$, Nikos Polyzos ${ }^{3,}$,, John Yfantopoulos ${ }^{4}$ \\ ${ }^{1}$ Department of Medical Laboratories, Technological University (TEI) of Thessaly, Larissa, Greece \\ ${ }^{2}$ Department of Businesses' and Organizations' Administration, Technological University (TEI) of Peloponnese, Kalamata, Greece \\ ${ }^{3}$ Department of Social Administration and Political Sciences, Democritus University of Thrace (DUTH), Komotini, Greece \\ ${ }^{4}$ Department of Political Sciences and Public Administration, National (Capodestrian) University of Athens (EKPA), Athens, Greece
}

Email address:

npolyzos@socadm.duth.gr (N. Polyzos)

\section{To cite this article:}

Christos Zilidis, Catherine Kastanioti, Nikos Polyzos, John Yfantopoulos. Development of a Health Workeforce Monitoring System in Greece. Journal of Investment and Management. Vol. 4, No. 5, 2015, pp. 256-263. doi: 10.11648/j.jim.20150405.27

\begin{abstract}
Background: Recent Greek economic crisis has had a mayor impact on healthcare system. A complete absence of planning human resources leeds to a need for healthcare workforce management tools, among them a re-distribution at a national and regional level following international indicators. Objectives: Aim of the study was to collect data on the current and future demand for and supply of human resources in the Greek health system, to map these data and finally to propose a model for future projections or actions. Methods: Data collected from various sources mainly of Ministry of Education for the supply and Ministry of Health for the demand. These data were aggregated in order tables to be standardized for future standard collection by these Ministries and the National Statistical Authority. The proposed model constitutes a combination between a stock-and-flow model and a workforce-to-population ratio approach. Results: Greece insists to an obvious oversupply of health professionals (over 7.000 annually), while demand can not absorb over 20-25\% of these staff. Due to economic crisis, there is an urgent need for reinforcing especially public sector in terms of new hires mainly of nursing and midwifery staff, and re-distribution of all. Conclusions: The main results indicate that health policy makers could reach an optimal matching between future supply of and demand for healthcare workforce by adjusting the flexible supply components. This presupposes an accurate and stable system of data collection. On the demand side, it is also important to collect demographics and other related data that are more indicative of health needs.
\end{abstract}

Keywords: Human Resources, Education, Health, Demand, Supply, Planning, Indicators, Projections

\section{Introduction}

Health sector is a highly labor intensive production process and it is one of the most significant sectors of the European Economy. According to Eurostat (1), in 2010, there were around 17.1 million Europeans employed in the health sector which accounted for $8 \%$ of the total labor force. During the 2000 - 2010 period the number of jobs in the health sector increased by $21 \%(2-5)$. The distribution across countries, taking the mobility into account, especially in Europe (6-8), is another special issue to be examined.

There is a growing interest in the development of methodologies for integrated approaches to planning and forecasting of health workforce, with the overall objective to develop effective interventions to better match demand and supply of health professionals (9-10). Towards that, a multispectral approach is needed in forecasting future demand and supply of human resources in the health sector, along with forecasting demographic and population's health needs in conjunction with technological changes, resource constraints and health expenditure restrictions (11).

In an economic crisis environment, there is an additional need to redefine health objectives and priorities in order to tackle the problems of health inequalities and the inefficiencies in the production and distribution of health services (12).

GIZ (German NGO) and DUTH (Democritus University of Thrace) were contracted in 2014 in order to study factors that are related to current and future demand for and supply of human resources in the Greek health system. This study finished in March 2015. Responsible for GIZ was Dr. Franz non Roenne (and colleagues) and for DUTH Prof. Nikos 
Polyzos (and a scientific team). This study aims to develop a methodology to monitor workforce developments in health sector in Greece, which can be used in health manpower planning, in the frame of the restrictions coming from the long-standing economic crisis. Models from other countries and organizations were examined (13-14), especially WHO templates etc. (15-16). Data mainly from the Greek Ministries of Education and Health were collected and aggregated.

\section{Methods}

The study focus on finding the sources of $\mathrm{HRH}$ information based on "stock and flow" approach (figute 1).

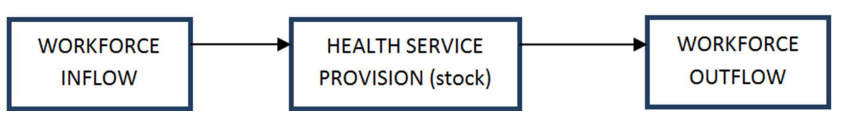

Figure 1. Process of workforce flow in the health sector.

This research included the first attempt to systematically identify a. the national system tracking at the same time graduates of health professions education programmes, international immigration of workers with health-related skills or exits due to career change, b. the stock and distribution of health workforce in Greek NHS, through gathering and synthesizing data from different available sources and including flows into and out of the health manpower. HRH data mapping template $(17, \mathrm{WHO}$, version 2.2) tool was deemed most appropriate and was primarily administered through email exchanges with the above sources. Follow-up telephone interviews were then conducted to complete the template.

To meet the aim of the study, three human resources management tools were developed:

a. A classification of health professions

b. A set of Health Manpower Indicators

c. An identification of a set of data sources needed.

Health Professions Classification. The first step in developing a health workforce monitoring system is to establish a classification of health professions. In order to ensure comparability, the classification of health professions should take into consideration internationally standardized classifications for social and economic statistics, such as (a) the ILO's International Standard Classification of Occupations 2008 (ISCO-08), and (b) the United Nation's International Standard Classification of Education 2011 (ISCED). The classifications were appropriately modified and adapted to meet the detailed needs of health manpower planning and to adapt them to the national specificities on health profession profiles. A Classification of Health Professions was developed (see below).

1. Physicians

1.1. General Practitioners

1.2. Specialist physicians of all other medical specialties (excluding General Practitioners)

1.3. Trainee physicians of all specialties

1.4. Physicians without specialty

\subsection{Dentists}

2. Nursing workforce

2.1. Qualified (registered) nurses

2.2. Qualified (registered) midwives

2.3. Assistant nurses

2.4. Ambulance crews \& bearers

2.5. Other auxiliary nursing personnel

3. Public Health workforce

3.1. Health visitors and community nurses

3.2. Public Health Inspectors

3.3. Veterinarians working in health sector per

3.4. Other public health professions

4. Long-term care and rehabilitation workforce

4.1. Physiotherapists

4.2. Occupational therapists

4.3. Speech therapists

4.4. Estheticians

4.5. Assistant Physiotherapists

4.6. Other auxiliary rehabilitation personnel

4.7. Home-care personal assistants and domestic assistants

5. Other scientific health professions

5.1. Pharmacists

5.2. Biochemists

5.3. Biologists and Molecular Biologists

5.4. Dieticians

5.5. Psychologists

5.6. Assistants of $5.1-5.5$ professions

6. Technological heath workforce

6.1. Higher education technological personnel

6.2. Medical Laboratory Technicians

6.3. X-ray Laboratory Technicians

6.4. Medical Equipment Technicians

6.5. Dental Technicians

6.6. Opticians

6.7. Medical Laboratory Technician Assistants

6.8. Craftsmen and maintenance workers

6.9. Drivers

6.10 Other technical personnel

7. Administrative workforce

7.1. Health and Welfare Units Management

7.2. Management and Economics

7.3. Health Informatics

7.4. Office Assistants and Secretaries

7.5. Housekeeping and maintenance personnel (except dieticians)

7.6. Security personnel

7.7. Other auxiliary personnel

8 . Health industry workforce

8.1. Pharmaceutical production and trading industry workforce

8.2. Medical supplies production and trading industry workforce

8.3. Medical laboratory reagents production and trading industry workforce

8.4. Medical equipment production, maintenance and trading industry workforce

8.5. Health information systems production and trading 
industry workforce

8.6. Medical tourism industry workforce

8.7. Private sector health insurance workforce

8.8. Private sector health training workforce

8.9. Other health industry workforce

Health Workforce Indicators. To map human resources in Greek health sector, a set of Health Workforce Indicators was developed. This set of indicators follows a "stock and flow" model, which can describe both inflow and outflow of the health workforce market. The set includes 5 categories of indicators: (a) Health workforce production indicators, (b) Population-based indicators, (c) Health workforce distribution indicators, (d) workforce efficiency indicators and (e) Outflow indicators.

Health workforce production indicators describe the workforce inflow to the total health system. The workforce inflow includes (i) the domestic production of health professions and (ii) the health professions inflow from other counties, both of Greek and non-Greek origin people.

Population-based indicators measure the availability of health personnel per 100,000 people. They provide: (i) a measurement of quantitative adequacy of the various categories of health workforce, (ii) a set of indices to investigate inequalities in human resources availability and distribution, as well as inequalities in health service provision and finally, (iii) a set of indicators to evaluate efficiency of human resources.

Health workforce distribution indicators describe the distribution of health workers into the health sector, in terms of proportions and ratios of health personnel in the various parts of health sector. They provide tools to examine inadequacies and inequalities in health services staffing, and help in prioritizing needs.

Workforce efficiency indicators measure the health services output in relation to personnel. They provide a measure of workforce productivity and efficiency of human resources.

Outflow indicators describe the rate of personnel withdrawals from the health sector.
Data sources. We conducted Ministry of Health and other government agencies with HRH roles (e.g. Ministry of Education, Labour, Administrative Reform and eGovernment) and Hellenic Statistical Authority (EL.STAT.), supported by Ministry of Health, in order to combine different types of information scattered across different sources. Data sources identification follows the same "stock and flow" model and includes sources that provide data needed for each one category of indicators. The model was tested on mapping health workforce facts of Greece of 2013, as well as in forecasting short-term personnel needs.

\section{Results}

Inflow indicators. Base on data collected from the sources reported, indicators describing the dynamics of workforce inflow in each professional category were calculated.

Table 1 demonstrates the total production of healthcare professions from both Greek and foreign Universities in 2013. The greatest workforce production is related to the medical profession $(10.8 / 100,000)$ closely followed by Psychologist profession (10.7/100.000). On the other hand, nurse production shows a rate of only $1.9 / 100,000$, which is lower compared to other developed countries (18). The average annual production of Medical Doctors corresponds to $1.7 \%$ of the existing "stock" of respective workforce whereas university level nurse production reaches $6.5 \%$, pharmacists production $3.1 \%$ and dentists $1.5 \%$. A lack of sufficient data on existing "stock" of workforce of other professions raises obstacles in calculating the respective indicator of other health related professions. However, substitution of doctors by nurses should be examined, mainly in Primary Health Care (19), especially during this crisis (20).

Table 2 shows the proportion of health professionals' production abroad to overall inflows that reaches $20.7 \%$ in pharmacists, $15.8 \%$ in dentists, $12.7 \%$ in Medical Doctors, but only $3.9 \%$ in nurses.

Table 1. Health professionals' production from domestic universities per 100,000 population, 2013.

\begin{tabular}{llll}
\hline Health profession & Graduates & per 100,000 population & Number of new professionals per 100 existing \\
\hline Medicine & 1,165 & 10.8 & 1.7 \\
Nursing & 204 & 1.9 & 6.5 \\
Dentistry & 209 & 1.9 & 1.5 \\
Pharmacy & 352 & 3.3 & 3.1 \\
Biology - Biotechnology & 504 & 4.7 & $\ldots$ \\
Nutrition and Dietetics & 36 & 0.3 & $\ldots$ \\
Psychology & 1,153 & 10.7 & $\ldots$ \\
Veterinary Medicine & 152 & 1.4 & $\ldots$ \\
Midwifery & 132 & 1.2 & $\ldots$ \\
Nursing & 1,247 & 11.5 & 3.4 \\
Dental Technology & 65 & 0.6 & $\ldots$ \\
Aesthetics and Cosmetology & 193 & 1.8 & $\ldots$ \\
Medical Instrument Technology & 75 & 0.7 & $\ldots$ \\
Medical Laboratories & 278 & 2.6 & $\ldots$ \\
Nutrition and Dietetics & 157 & 1.5 & $\ldots$ \\
Optics and Optometry & 102 & 0.9 & $\ldots$ \\
Physiotherapy & 428 & 4.0 & $\ldots$ \\
Radiology & 43 & 0.4 & $\ldots$ \\
\hline
\end{tabular}




\begin{tabular}{llll}
\hline Health profession & Graduates & per 100,000 population & Number of new professionals per 100 existing \\
\hline Speech \& Language Therapy & 249 & 2.3 & $\ldots$ \\
Ocupational Therapy & 74 & 0.7 & $\ldots$ \\
Public Health & 132 & 1.2 & $\ldots$ \\
Social work & 340 & 3.1 & $\ldots$ \\
Health Management & 242 & 2.2 & $\ldots$ \\
Assistant midwifery & 6 & 0.1 & $\ldots$ \\
Assistant nursing & 875 & 8.1 & 12.1 \\
Other dental care services & 32 & 0.3 & $\ldots$ \\
Assistant Physiotherapist & 349 & 3.2 & $\ldots$ \\
Medical laboratory technology & 293 & 2.7 & $\ldots$ \\
Pharmacy and Cosmetic Technology & 216 & 2.0 & $\ldots$ \\
Medical Information technology & 20 & 0.2 & $\ldots$ \\
\hline
\end{tabular}

Table 2. Health professionals' production from Greek and foreign universities, 2013.

\begin{tabular}{lllll}
\hline Health Profession & Domestic Universities & Foreign Universities & TOTAL & Foreign Universities (\%) \\
\hline Medical Doctors & 1,017 & 148 & 1,165 & $12.7 \%$ \\
Dentists & 176 & 33 & 209 & $15.8 \%$ \\
Pharmacists & 279 & 73 & 352 & $20.7 \%$ \\
Qualified nurses & 196 & 8 & 204 & $3.9 \%$ \\
\hline
\end{tabular}

Table 3. Population based indicators of selective health professions by region, 2013.

\begin{tabular}{lllll}
\hline Regions & Medical Doctors per 100,000 & Dentists per 100,000 & Pharmacists per 100,000 & Physio- therapists per 100,000 \\
\hline Attiki & 892.9 & 179.2 & 110.8 & 72.3 \\
Sterea Ellada & 311.5 & 88.4 & 92.6 & 43.8 \\
Dytiki Ellada & 553.8 & 96.4 & 97.4 & 46.9 \\
Peloponnisos & 391.2 & 99.5 & 97.6 & 40.8 \\
Thessaly & 480.8 & 111.8 & 110.5 & 42.4 \\
Ipeiros & 599.7 & 102.4 & 98.3 & 39.5 \\
East Macedonia \& Thraki & 482.6 & 88.5 & 92.1 & 55.9 \\
Central Macedonia & 602.6 & 126.4 & 112.9 & 56.0 \\
West Macedonia & 301.7 & 95.5 & 108.6 & 38.8 \\
Ionia Nisia & 409.4 & 81.3 & 89.5 & 53.9 \\
North Aigaio & 399.0 & 80.3 & 99.9 & 41.7 \\
South Aigaio & 367.3 & 96.4 & 95.5 & 34.3 \\
Kriti & 618.2 & 105.1 & 84.6 & 45.9 \\
Total & 640.0 & 131.4 & 104.6 & 56.4 \\
\hline
\end{tabular}

Population based indicators and regional distribution of health workforce. Table 3 reports the density of four selective health professions per 100,000 by region. Region of Attica (region of Athens) shows the largest numbers in almost all cases. In three of four professions, Attica is the only region above the national average. Regarding Pharmacists, Central and West Macedonia as well as Thessaly are also above the national average. Table 4 shows a large concentration of medical professions in the Greater Athens area.

Table 4. Medical Doctors per 100.000 population, by medical specialty and region (2013).

\begin{tabular}{|c|c|c|c|c|c|}
\hline Region & $\begin{array}{l}\text { Medical Doctors } \\
\text { per } 100,000\end{array}$ & $\begin{array}{l}\text { Generalist Medical } \\
\text { Doctors per } 100,000\end{array}$ & $\begin{array}{l}\text { Specialist Medical } \\
\text { Doctors per } 100,000\end{array}$ & $\begin{array}{l}\text { Doctors without a medical } \\
\text { specialty per } 100,000\end{array}$ & $\begin{array}{l}\text { Dentists per } \\
100,000\end{array}$ \\
\hline Attiki & 892.9 & 9.7 & 514.5 & 368.7 & 179.2 \\
\hline Sterea Ellada & 311.5 & 28,0 & 208,0 & 75.6 & 88.4 \\
\hline Dytiki Ellada & 553.8 & 28.5 & 303.8 & 221.5 & 96.4 \\
\hline Peloponnisos & 391.2 & 34.6 & 222.1 & 134.6 & 99.5 \\
\hline Thessalia & 480.8 & 24.3 & 302.1 & 154.3 & 111.8 \\
\hline Ipeiros & 599.7 & 32.1 & 393.3 & 174.3 & 102.4 \\
\hline Central Macedonia & 603.2 & 26.3 & 385.6 & 191.3 & 126.5 \\
\hline West Macedonia & 301.7 & 22.9 & 206.1 & 72.6 & 95.5 \\
\hline Ionia Nisia & 409.4 & 20.2 & 265.5 & 123.6 & 81.3 \\
\hline North Aigaio & 399.0 & 27.6 & 253.5 & 118,0 & 80.3 \\
\hline South Aigaio & 367.3 & 27.5 & 241.5 & 98.4 & 96.4 \\
\hline Kriti & 618.2 & 38.7 & 351.8 & 227.7 & 105.1 \\
\hline Greece, total & 640.0 & 21.9 & 380.2 & 237.8 & 131.4 \\
\hline
\end{tabular}


Table 5. Hospital personnel per 100 beds, by category, in public and private hospitals (2013)

\begin{tabular}{llll}
\hline Personnel by category per 100 beds & Public & Private & Total \\
\hline Medical Doctors & 65.6 & 55.3 & 61.8 \\
Nursing personnel & 108.1 & 42.3 & 84.0 \\
Administrative personnel & 24.9 & 14.6 & 21.1 \\
Other health professions & 9.0 & 9.0 & 9.0 \\
Technical and other health associate professionals & 35.0 & 14.3 & 27.4 \\
Other health associate professionals & 14.7 & 0.0 & 9.3 \\
Total & 257.3 & 135.5 & 212.7 \\
\hline
\end{tabular}

Table 5 indicates the number of Medical Doctors per 100,000 population by medical specialty and region. In average, there are only 21.9 Generalist Medical Doctors per 100,000 vs 380.2 Specialist Medical Doctors. However, the rate of Generalist Medical Doctors is much lower in the Attica region $(9.7 / 100,000)$ whereas the rate of Specialist Medical Doctors is much higher $(514.5 / 100,000)$. Both should be awared the policy makers, taken into account international standards (Watson et al, 2006).

Health workforce distribution. Table 6 reports the total number of hospital personnel per 100 beds, by category of personnel, in public and private hospitals (34,092 and 19,681 hospital beds respectively). Staffing in private hospitals is found to be significantly lower compared to public hospitals, in almost all categories of health personnel. Similar indicators can be calculated by region.

Table 6. Population-based NHS workforce indicators.

\begin{tabular}{|c|c|c|c|c|c|c|c|c|}
\hline \multirow{2}{*}{ Population-based nhs workforce indicators } & \multicolumn{8}{|c|}{ Health Region } \\
\hline & 1 & 2 & 3 & 4 & 5 & 6 & 7 & Total \\
\hline Medical doctors / physicians per 100.000 & 198.9 & 346.7 & 135.6 & 243.5 & 148.4 & 204.3 & 237.7 & 206.9 \\
\hline Nursing and midwifery professionals per 100.000 & 151.1 & 254.8 & 131.6 & 227.4 & 126.3 & 167.5 & 209.1 & 170.7 \\
\hline Other health professionals per 100.000 & 26.5 & 66.1 & 22.4 & 26.0 & 17.8 & 24.9 & 28.9 & 28.5 \\
\hline Medical and pharmaceutical technicians per 100.000 & 34.6 & 52.4 & 25.3 & 42.2 & 25.2 & 31.6 & 32.1 & 34.2 \\
\hline Nursing \& midwifery assistants per 100.000 & 124.1 & 274.7 & 103.0 & 176.8 & 130.3 & 187.5 & 170.0 & 155.9 \\
\hline Other health associate professionals per 100.000 & 33.6 & 89.3 & 28.3 & 58.0 & 38.0 & 52.3 & 54.2 & 46.0 \\
\hline Personal care workers in NHS per 100.000 & 9.8 & 38.3 & 9.4 & 10.8 & 12.9 & 15.8 & 12.4 & 14.1 \\
\hline Administrative personnel per 100.000 & 67.0 & 153.9 & 51.5 & 77.9 & 63.6 & 84.6 & 89.7 & 78.3 \\
\hline Technical \& other per 100.000 & 54.8 & 160.3 & 52.9 & 73.9 & 66.7 & 90.8 & 86.3 & 76.1 \\
\hline Health personnel not elsewhere classified & 1.1 & 0.1 & 0.3 & 0.2 & 0.0 & 0.1 & 0.0 & 0.4 \\
\hline Total & 701.4 & $1,436.4$ & 560.5 & 936.7 & 629.2 & 859.3 & 920.4 & 811.1 \\
\hline
\end{tabular}

Table 7 shows the population-based NHS personnel indicators across the seven Health Regions (DYPE) of the country. In the whole NHS, Medical Doctors constitute the largest group of professionals $(206.9 / 100,000)$ followed by nursing personnel $(170.7 / 100,000)$. Significant inequalities are shown across Health Regions.

Table 8 describes the distribution of NHS personnel between hospitals and PHC sector. In total, $92.2 \%$ of the whole NHS workforce is employed in hospitals and 7,8 \% in PHC units. However, this proportion drops to $3,5 \%$ in nursing personnel and increases to $14.6 \%$ in medical personnel.

Table 9 presents NHS hospital personnel per 100 hospital beds, across Health Regions. Significant inequalities are found among Health Regions, in most categories of hospital personnel. In all Regions, qualified nurses in hospitals are less than medical doctors, and they constitute $52,3 \%$ of all nursing personnel (assistants included). Table 12 provides further information on the proportional distribution of NHS nurses (both hospital and PHC included) by educational level across Health Regions.

Table 7. NHS personnel distribution in hospitals and PHC* centers.

\begin{tabular}{lllllll}
\hline & & N & & & (\%) \\
\hline & Hospitals & PHC & Total & Hospitals & PHC & Total \\
\hline Physicians & 20,824 & 3,574 & 24,398 & 85.4 & 14.6 & 100 \\
Nursing personnel & 33,969 & 1,223 & 35,192 & 96.5 & 3.5 & 100 \\
Administrative personnel & 7,916 & 455 & 8,371 & 94.6 & 5.4 & 100 \\
Other health personnel & 10,309 & 1,385 & 11,694 & 88.2 & 11.8 & 100 \\
Technical personnel & 8,004 & 118 & 8,122 & 98.5 & 1.5 & 100 \\
Personal care workers & 1,344 & 177 & 1,521 & 88.4 & 11.6 & 100 \\
Total & 82,366 & 6,932 & 89,298 & 92.2 & 7.8 & 100 \\
* Prtimary Health Care & & & & & & \\
\hline
\end{tabular}


Table 8. NHS hospital personnel per 100 beds.

\begin{tabular}{|c|c|c|c|c|c|c|c|c|}
\hline \multirow{2}{*}{ hospital personnel indicators } & \multicolumn{7}{|c|}{ health region } & \multirow{2}{*}{ Total } \\
\hline & 1 & 2 & 3 & 4 & 5 & 6 & 7 & \\
\hline Medical doctors per 100 beds & 73.2 & 57.5 & 49.1 & 67.6 & 75.7 & 68.9 & 65.1 & 65.6 \\
\hline Nursing and midwifery professionals per 100 beds & 55.6 & 42.2 & 47.7 & 63.1 & 64.4 & 56.5 & 57.3 & 54.1 \\
\hline Other health professionals per 100 beds & 9.8 & 11.0 & 8.1 & 7.2 & 9.1 & 8.4 & 7.9 & 9.0 \\
\hline Medical and pharmaceutical technicians per 100 beds & 12.7 & 8.7 & 9.2 & 11.7 & 12.8 & 10.6 & 8.8 & 10.8 \\
\hline Nursing \& midwifery assistants per 100 beds & 45.6 & 45.5 & 37.3 & 49.1 & 66.5 & 63.2 & 46.5 & 49.4 \\
\hline Total nursing personnel per 100 beds & 101.2 & 87.8 & 85.0 & 112.1 & 130.9 & 119.7 & 103.8 & 103.6 \\
\hline Other health associate professionals per 100 beds & 12.4 & 14.8 & 10.3 & 16.1 & 19.4 & 17.6 & 14.9 & 14.6 \\
\hline Personal care workers in NHS per 100 beds & 3.6 & 6.3 & 3.4 & 3.0 & 6.6 & 5.3 & 3.4 & 4.5 \\
\hline Administrative personnel per 100 beds & 24.7 & 25.5 & 18.7 & 21.6 & 32.4 & 28.5 & 24.6 & 24.9 \\
\hline Technical \& other per 100 beds & 20.1 & 26.6 & 19.2 & 20.5 & 34.0 & 30.6 & 23.6 & 24.1 \\
\hline Health personnel not elswere classified & 0.4 & 0.0 & 0.1 & 0.1 & 0.0 & 0.0 & 0.0 & 0.1 \\
\hline Total & 258.0 & 238.2 & 203.0 & 259.9 & 320.9 & 289.8 & 252.1 & 257.3 \\
\hline
\end{tabular}

Table 9. Proportional (\%) distribution of NHS nurses by educational level and Health Region.

\begin{tabular}{|c|c|c|c|c|c|c|c|c|}
\hline \multirow{2}{*}{ Education Level } & \multicolumn{7}{|c|}{ Health Region } & \multirow{2}{*}{ Total } \\
\hline & $1 \mathrm{st}$ & $2 d$ & 3d & 4th & 5 th & 6th & 7th & \\
\hline Qualified nurses & 60.3 & 49.8 & 58.3 & 56.0 & 56.5 & 54.3 & 61.4 & 56.5 \\
\hline Assistant nursing personnel & 39.7 & 50.2 & 41.7 & 44.0 & 43.5 & 45.7 & 38.6 & 43.5 \\
\hline Total & 100.0 & 100.0 & 100.0 & 100.0 & 100.0 & 100.0 & 100.0 & 100.0 \\
\hline
\end{tabular}

Workforce efficiency indicators. Table 10 surmises workforce efficiency indicators (i) average annual admissions and (ii) average hospital days per staff member, by Health Region. Data of table 14 show substantial differentiation among Regions in these indicators, in almost all categories of hospital personnel. Average annual admissions per doctor varies from 86 to 133.2 across Health Regions, while average annual hospital days per doctor ranges from 325.2 to 521.5. Similarly, average annual admissions per qualified nurse ranges from 115.3 to 137.3 , while average annual hospital day per qualified nurse from 356.1 to 537.4 . These findings revealed significant variation in workforce efficiency across Health Regions.

Outflow indicators. Table 11 presents personnel outflow indicators, by Health Region, per 100,000 population. Retirement with resignation constitutes the major reason for exiting the healthcare workforce. Significant variation among Regions can be observed, which mainly are due to differences in age-maturity of health personnel across the country.

Table 10. Annual admissions and hospital days per staff member, by Health Region.

\begin{tabular}{|c|c|c|c|c|c|c|c|c|}
\hline \multirow[t]{2}{*}{ hospital efficiency indicators } & \multicolumn{8}{|c|}{ Health Region } \\
\hline & 1st & 2d & 3d & 4th & 5th & 6th & 7th & Total \\
\hline Average annual admissions per physician & 96.0 & 86.0 & 133.2 & 107.7 & 108.7 & 100.7 & 101.7 & 101.6 \\
\hline Average annual admissions per nurse/midwife & 126.4 & 117.1 & 137.3 & 115.3 & 127.7 & 122.8 & 115.6 & 123.2 \\
\hline Average annual admissions per other health professional & 720.2 & 451.3 & 808.2 & 1007.1 & 905.5 & 827.5 & 836.9 & 737.8 \\
\hline Average annual admissions per assistant nursing personnel & 153.9 & 108.6 & 175.4 & 148.3 & 123.8 & 109.7 & 142.2 & 134.9 \\
\hline Average annual admissions per total nursing personnel & 69.4 & 56.3 & 77.0 & 64.9 & 62.9 & 57.9 & 63.8 & 64.4 \\
\hline Average annual hospital days per nurse/midwife & 488.6 & 468.3 & 537.4 & 356.1 & 382.1 & 440.1 & 418.2 & 475.8 \\
\hline Average annual hospital days per other health professional & 2196.9 & 1907.8 & 2496.1 & 1396.6 & 1268.8 & 1410.4 & 1612.1 & 1767.0 \\
\hline Average annual hospital days per assistant nursing personnel & 594.9 & 620.0 & 686.6 & 458.0 & 370.4 & 393.1 & 514.5 & 521.0 \\
\hline Average annual hospital days per total nursing personnel & 268.3 & 321.6 & 301.4 & 200.3 & 188.1 & 207.6 & 230.7 & 248.7 \\
\hline
\end{tabular}

Table 11. Personnel outflow indicators by Health Region per 100,000 population.

\begin{tabular}{|c|c|c|c|c|c|c|c|c|}
\hline \multirow[t]{2}{*}{ outflow indicators by health region PER 100.000 population } & \multicolumn{8}{|c|}{ Health Region } \\
\hline & 1st & 2d & 3d & 4th & 5th & 6th & 7th & Total \\
\hline Retirement with resignation & 6.2 & 9.5 & 4.8 & 5.3 & - & 7.8 & 10.4 & 6 \\
\hline Compulsory retirement with age limit and 35 -year service & 0.4 & 0 & 0.1 & 0 & - & 0.2 & 0.2 & 0.2 \\
\hline Compulsory retirement with 35 -year service and 67 age limit & 0.1 & 0.1 & 0.1 & 0.3 & - & 0 & 0.2 & 0.1 \\
\hline Early retirement with 35 -year service and 55 age limit & 0.5 & 0.1 & 0 & 0.1 & - & 0 & 0 & 0.2 \\
\hline Early retirement with 35 -year service and 55 age limit up to $31-12-2013$ & 0.7 & 0.5 & 0.2 & 0.2 & - & 0 & 0.2 & 0.3 \\
\hline
\end{tabular}




\section{Discussion}

Like many other countries, in Greece, comprehensive data on human resources are not available in one single repository (21), as there is not a national system tracking data from all sources listed, like OECD referred (22-23). This means that any attempt to determine the size and core characteristics of the health workforce requires some level of analysis and synthesis of available information from multiple sources. Some of the main problems occurring in gathering appropriate data are: (i) data on health professions that, apart from the health sector, work in other sectors too, (ii) data on health professionals abroad graduated, in professions that have no obligation for a recognition of their qualifications, (iii) retirement and other reason of withdrawals from work in health sector, (iv) employment of medical doctors in private hospitals etc. A particular problem we faced is the uncertainty on health workforce availabiblity introduced of the high proportion of unemployment.

The set of Health Workforce Indicators developed follows a "stock and flow" model, based on international literature (24) and WHO methodology (7, 17, and 21). The quality and adequacy of available data led to a combination between the workforce-to-population ratio and the health needs method concerning demand projections, while supply projections were performed using the stock-and-flow model. Concerning demand projections we forecasted domestic population over the period 2015-2020 using an ARIMA $(0,2,1)$ model. Apart from the normal forecast two extreme scenarios were developed too. The main conclusion is that demand for HRH in Greece is expected to follow an average downward trend over the examined period mainly due to the expectations of decreasing population. However the model is highly sensitive to population numbers, hence accuracy will be achieved through annual adjustment to actual population developments, as well as the total work-force (mainly the solo-practice added). The results from this modeling have already published (25) and referred in the below summary.

\section{Conclusion}

In fact, the above results based on specific indicators were essential in order to implement some of the core human resource management policies namely human resource planning and recruitment (26). To elaborate more, being aware of the number of employees working in health care organizations facilitates their effective allocation and distribution and it leads to the projection of workforce needs in the future (27). The main results of this phase of the study are the following:

1. Universities' system provides many doctors and psychologists (11/100,000 p.), while nurses' and others' population ratios is similar or even better only due to technological and secondary education. However, nurses' employment should be immediately increased, mainly to the NHS.
2. Work-force distribution indicates inequalities among regions mainly in favour of Attica, Salonika and Crete. This is the case among professions or medical specialties.

3. Efficiency indicators reveal discrepancies among professions and regions too.

4. Outflow indicators vary among regions (and professions) concerning work-force/population ratios. Athens' area shows the higher ratio of exits, mainly due to retirements, all-though other reasons were not available from the data.

5. The development of classification and health workforce indicators is important for Greece, thus we provide this in accordance with a set of health workforce and other indicators.

General findings of the study contract (between GIZ and DUTH) indicate the following:

A. On the supply side, every year, over 7.000 health professionals were graduated from the Greek higher education, 2.000 from secondary education, and over 230 from abroad (officially). The main problem of all those professionals is the limited offer of jobs either in public or in private sector.

B. On the demand side, 87.000 health workers employed in the NHS and at least 26.000 in private hospitals and clinics. It is estimated that still 37.000 doctors are in the private (solo practice or diagnostic) sector and approximately $20 \%$ of them are contracted with EOPYY (National Organization of Health Service Provision that is the newly established Unified Fund of Social Security Sickness Fund). Concerning doctors, pharmacists, dentists, etc. ratios, Greece has the highest numbers per population, compared to international data.

C. Thus, the education system in collaboration with the health system needs an immediate plan to match the relevant demand and supply of the future, taking into account the restrictions and limitations referred in the conclusion of the study.

In conclusion, it was infeasible to examine the health needs model, if the national statistical authority (EL.STAT.) or/and "health.map" do not record all demographics and health related data that should potentially quantify health needs. Next, more accurate data is included in the study for future projections. Finally, we developed templates to ensure intergraded, accurate and universal data collection. These templates should constitute the main business components of the relevant HRM software that has to be established immediately.

\section{References}

[1] Eurostat (2014) Disaggregated data for the healthcare sector.

[2] Alcimed (2010) Study on Healthcare Services, Sectors and Products in Europe for the European Commission. Final Report February 2010. 
[3] European Commission (2010) Conclusions of the 3053rd EPSCO Council meeting. Brussels, 7 December 2010. Investing in Europe's health workforce of tomorrow: Scope for innovation and collaboration.

[4] European Commission (2011) Proposal for a Health for Growth Programme 2014-2020, COM (2011) 709 final of 9.11.2011.

[5] European Commission (2012) RN4CAST Report. Nurse forecasting: Human resources planning in nursing. 12 European countries (Belgium, UK, Finland, Germany, Greece, Ireland, Norway, Poland, Spain, Sweden, Switzerland and Netherlands) and also USA, China, Botswana and South Africa.

[6] Maier, CB. et al. (2011) Cross-country analysis of health professional mobility in Europe: the results. In Wismar $M$ et al., eds. Health professional mobility and health systems. Evidence from 17 European countries. Copenhagen,

[7] World Health Organization (2011) Regional Office for Europe, Copenhagen: Study by M. Wismar, C. B. Maier, I. A. Glinos, G. Dussault and J. Figueras (eds., 2011), Health professional mobility and health systems. Evidence from 17 European countries, Observatory Study Series No. 23, European Observatory on Health Systems and Policies.WHO Regional Office for Europe on behalf of the European Observatory on Health Systems and Policies.

[8] Jelfs, E. (2012) Workforce issues in European Union health policy. Health Service Management Research, 25:48-49.

[9] O'Brian-Pallas, L., Baumann, A., Donner, G., Murphy, G., Lochhaas-Gerlach, J. and Luba, M. (2001) Forecasting models for human resources in health care. Journal of Advanced Nursing, 33(1):120-129.

[10] Ono, T., Lafortune, G. and Schoenstein, M. (2013) Health workforce planning in OECD countries: a review of 26 projection models from 18 countries. Paris, Organisation for Economic Co-operation and Development (OECD Health Working Paper 62).

[11] Stuckler, D. et al. (2011) Effects of the 2008 recession on health: a first look at European data. Lancet, 378:124-125.

[12] Buchan, J., O’May, F. and Dussault, G. (2013) The nursing workforce and the global economic crisis. Journal of Nursing Scholarship, 45(3):298-307.

[13] Joyce, C. and McNeil, J. (2006) Participation in the workforce by Australian medical graduates. Medical Education, 40(4):333-339.

[14] Canadian Academy of Health Sciences (2009) Making an Impact, A Preferred Framework and Indicators to Measure Returns on Investment in Health Research. FullReport.pdf

[15] World Health Organization (2001) Toolkit for Planning, Training and Management. Projecting Workforce Requirements: Planning with the WHO Scenario Models. World Health Organization: Geneva.
[16] World Health Organization (2010) Policy Brief How to create an attractive and supportive working environment for health professionals, Health Evidence Network and the European Observatory on Health Systems and Policies.

[17] World Health Organization (2010) Models and tools for health workforce planning and projections. World Health Organization: Geneva.

[18] European Federation of Nurses Associations (2012) Caring in crisis: the impact of the financial crisis on nurses and nursing. A comparative overview of 34 European countries. Brussels, European Federation of Nurses Associations.

[19] Laurant, M., Reeves, D., Hermens, R., Braspenning, J., Grol, R. and Sibbald, B. (2004) Substitution of doctors by nurses in primary care. John Wiley \& Sons Ltd.: Chichester, UK.

[20] Staiger, D., Auerbach, D. and Buerhaus, P. (2012) Registered nurse labor supply and the recession: are we in a bubble? New England Journal of Medicine, 366:1463-1465.

[21] World Health Organization (2013) The health workforce: advances in responding to shortages and migration, and in preparing for emerging needs. Geneva, World Health Organization (Report by the Secretariat for the Sixty-sixth World Health Assembly, Provisional Agenda Item 17.4) (http://apps.who.int/gb/ebwha/pdf_files/WHA66/A66_25en.pdf).

[22] OECD (2011) Health at a glance 2011: OECD indicators. Paris, Organization for Economic Co-operation and Development.

[23] OECD (2012) Health at a glance: Europe 2012. Paris, Organization for Economic Co-operation and Development.

[24] Sullivan, L. and Michel, I. (2004) Core Competencies in Public Health: Literature Review. Ontario Public Health Association, March 4, 2004. Accessed from http://www.opha.on.ca/corecompetencies/index.html June 2004.

[25] Polyzos, N., Karakolias, S., Mavridoglou, G., Gkorezis, P., Zilidis, C., (2015) Current and future insight into human resources in Greece. Open Journal of Social Sciences, v.3 (n.5): 5-14.

[26] Dreesch, N., Dolea, C., Dal Poz, M., Goubarev, A., Adams, O., Aregawi, M., Bergstrom, K., Fogstad, H., Sheratt, D., Linkins, J., Scherpbier, R. and Youssef-Fox, M. (2005) An approach to estimating human resource requirements to achieve the Millennium Development Goals. Health Policy and Planning, 20(5):267-276.

[27] World Health Organization (2004) World Report on Knowledge for Better Health: Strengthening Health systems. World Health Organization: Geneva. 